\title{
Validation of the 36 -item version of the WHO Disability Assessment Schedule 2.0 (WHODAS 2.0) for assessing women's disability and functioning associated with maternal morbidity Validação da versão de 36 itens do WHO Disability Assessment Schedule 2.0 (WHODAS 2.0) para a avaliação de incapacidade e funcionalidade da mulher associada à morbidade materna
}

\author{
Carla Silveira ${ }^{1}$ Mary Angela Parpinelli ${ }^{1}$ Rodolfo Carvalho Pacagnella ${ }^{1}$ Carla Betina Andreucci ${ }^{1,2}$ \\ Carina Robles Angelini ${ }^{1}$ Elton Carlos Ferreira ${ }^{1}$ José Guilherme Cecatti ${ }^{1}$ and the COMMAG study group \\ ${ }^{1}$ Department of Medicine, Obstetrics and Gynecology, Faculdade de \\ Ciências Médicas, Universidade Estadual de Campinas, Campinas, Brazil \\ 2 Universidade Federal de São Carlos (UFSCAR), São Carlos, SP, Brazil \\ Address for correspondence Jose Guilherme Cecatti, Departmento de \\ Obstetrícia e Ginecologia, Universidade Estadual de Campinas, Rua \\ Alexander Fleming, 101, 13083-891 Campinas, SP, Brazil \\ (e-mail: cecatti@unicamp.br).
}

Rev Bras Ginecol Obstet 2017;39:44-52.

\author{
Abstract \\ Keywords \\ - International \\ Classification of \\ Functioning \\ - Disability and Health \\ (ICF) \\ - pregnancy \\ complications \\ - validation studies \\ - maternal and child \\ health
}

Objective To validate the translation and adaptation to Brazilian Portuguese of 36 items from the World Health Organizaton Disability Assessment Schedule 2.0 (WHODAS 2.0), regarding their content and structure (construct), in a female population after pregnancy.

Methods This is a validation of an instrument for the evaluation of disability and functioning and an assessment of its psychometric properties, performed in a tertiary maternity and a referral center specialized in high-risk pregnancies in Brazil. A sample of 638 women in different postpartum periods who had either a normal or a complicated pregnancy was included. The structure was evaluated by exploratory factor analysis (EFA) and confirmatory factor analysis (CFA), while the content and relationships among the domains were assessed through Pearson's correlation coefficient. The sociodemographic characteristics were identified, and the mean scores with their standard deviations for the 36 questions of the WHODAS 2.0 were calculated. The internal consistency was evaluated byCronbach's $\alpha$.

Results Cronbach's $\alpha$ was higher than 0.79 for both sets of questons of the questionnaire. The EFA and CFA for the main 32 questions exhibited a total variance of 54.7\% (Kaiser-Meyer-Olkin [KMO] measure of sampling adequacy $=0.934 ; p<0.001$ ) and $53.47 \%(\mathrm{KMO}=0.934 ; p<0.001)$ respectively. There was a significant correlation received

September 25, 2016 accepted

December 7, 2016

published online

February 23, 2017
DOI http://dx.doi.org/

10.1055/s-0037-1598599. ISSN 0100-7203.
Copyright @ 2017 by Thieme-Revinter

Publicações Ltda, Rio de Janeiro, Brazil
License terms

(c) $(1) \$$ 


\section{Resumo}

\section{Palavras-chave}

- Classificação Internacional de Funcionalidade

- Incapacidade e Saúde (CIF)

- complicações na gravidez

- estudos de validação

- saúde materno-infantil among the 6 domains $(r=0.571-0.876)$, and a moderate correlation among all domains $(r=0.476-0.694)$.

Conclusion The version of the WHODAS 2.0 instrument adapted to Brazilian Portuguese showed good psychometric properties in this sample, and therefore could be applied to populations of women regarding their reproductive history.

Objetivo Validar a versão adaptada para o português brasileiro do instrumento World Health Organizaton Disability Assessment Schedule 2.0 (WHODAS 2.0), em seu conteúdo e estrutura (construto), em uma população de mulheres após a gravidez. Métodos Trata-se de validação de um instrumento para incapacidade e funcionalidade, incluindo suas propriedades psicométricas, realizada em uma maternidade de referência em gestação de alto risco no Brasil. Incluiu uma amostra de 638 mulheres em diferentes períodos pós-parto que tiveram uma gravidez normal ou com complicações. A estrutura foi avaliada por análise fatorial exploratória (AFE) e análise fatorial confirmatória (AFC), enquanto o conteúdo e as associações entre os domínios foram avaliados por meio do coeficiente de correlação de Pearson. Foram identificadas características sociodemográficas, e os escores médios do WHODAS 2.0 para as 36 questões foram calculados. A consistência interna foi avaliada pelo método $\alpha$ de Cronbach.

Resultados $\mathrm{O} \alpha$ de Cronbach foi maior do que 0,79 para os dois conjuntos de perguntas do questionário. A AFE e a AFC para as 32 questões apresentaram uma variância total de $54,7 \%$ (medida de adequação da amostra de Kaiser-Meyer-Olkin $[\mathrm{KMO}]=0,934 ; p<0,001)$ e 53,47\% (KMO $=0,934 ; p<0,001)$, respectivamente. Houve uma correlação significativa entre os 6 domínios ( $r=0,571-0,876)$, e moderada correlação entre todos os domínios ( $r=0,476-0,694)$.

Conclusão $\mathrm{O}$ instrumento WHODAS 2.0, adaptado para o português do Brasil, mostrou boas propriedades psicométricas nessa amostra e, portanto, pode ser aplicado a populações de mulheres com relação à sua história reprodutiva.

\section{Introduction}

Although both genders face similar challenges, women live longer in general. ${ }^{1}$ However, specific conditions only experienced by women may cause a negative impact on health, such as those from the reproductive period. Major functional changes occur during pregnancy, childbirth and the postpartum period, and they may either lead to maternal death or to different levels of morbidity. Then, a consequent reduction in the quality of life and functioning of women is observed, as well as a negative impact on their children and the economical and social burden for their families. ${ }^{2}$ Each year, 15 to 20 million women develop morbid conditions related to pregnancy, with a long-term reduction in functioning. ${ }^{3,4}$ Functioning is the human ability to perform activities, so individuals may take care of themselves and interact independently with society. ${ }^{5}$ Disability is the restriction or lack of the ability to develop normal functions. ${ }^{5,6}$ Both are conceived originating from the dynamic interaction between health conditions and contextual factors. 5,7

The interaction between health conditions and contextual factors was already demonstrated, and it showed that there is a decline in functioning with age that depends on the basal functioning. ${ }^{8}$ Some important studies also showed a remarkable decrease in functioning and frequent and more serious disabilities mainly in the elderly, poor people and women living in low-income countries. ${ }^{9,10}$

Various methods and instruments based on multidimensional conceptual models have been used to measure disability. They seek to evaluate health status and quality of life in the general population or in groups with special needs, addressing health through items related to physical, mental and social aspects. The World Health Organization Disability Assessment Schedule 2.0 (WHODAS 2.0) is an example of such methods. It considers the profile, functioning and disability of individuals in different cultures and languages, ${ }^{11}$ and it evaluates activity limitations and participation restrictions, regardless of the medical diagnosis, due to its solid theoretical foundations, adequate psychometric properties, applicability to different groups, in addition to being easy to use. $7,11,12$

There are two translated and adapted versions of the WHODAS 2.0 into Portuguese. The first was translated to 
Brazilian Portuguese in a female population in the postpartum period, ${ }^{13}$ and the other was translated to European Portuguese using a population suffering from musculoskeletal disabilities. ${ }^{14}$ Although the psychometric properties of the original instrument were well established in English, it is necessary to determine such properties for the version in Brazilian Portuguese. Taking into account the concepts of content and construct validity, ${ }^{15}$ the aim of the current study is to assess both in the Brazilian Portuguese version of the WHODAS 2.0 in a population of Brazilian women in reproductive age who had experienced previous pregnancies with and without severe maternal morbidity to assess the psychometric properties of this instrument for this specific population. This is necessary before recommending its routine use for assessing functioning possibly associated with pregnancy and maternal outcome.

\section{Methods}

\section{Design and Setting}

This is a validation study of the Brazilian Portuguese version of the WHODAS 2.0 among women admitted during pregnancy or the postpartum period to a tertiary referral maternity in the southeast region of Brazil from July 2008 to June 2012. This hospital is specialized in high-risk pregnancies, and has an obstetric intensive care unit (ICU) for cases of severe maternal morbidity.

\section{Participants}

Trained interviewers contacted women selected through the hospital admissions' database system by telephone, inviting them to participate in the retrospective cohort study of the multidimensional assessment of severe maternal morbidity. If the telephone contact was unsuccessful, an invitation letter was sent, explaining the study and asking the women to contact the interviewers back. Further methodological details about the study have already been published elsewhere. ${ }^{16,17}$ This validation study used the sample population of the retrospective cohort involving women who had a severe maternal morbidity episode due either to a WHO potentially life-threatening condition or maternal near miss conditions (both are here considered as having severe maternal morbidity and constituting the exposed group, 315 women, 49.4\%), and women whose childbirth had no complications (unexposed group, 323 women, $50.6 \%)^{16}$

A total of 840 women were eligible, and 638 were selected and invited for an interview. The group answered the WHODAS 2.0 questionnaire, and 202 women were not enrolled because they were not reached either by phone or letter, or even declined to participate. Two women were excluded from the analysis once they failed to answer one domain of the questionnaire, which was completely answered by 636 women. A total of 334 women did not have a job or were no longer in school, and answered only 32 questions of the instrument. Therefore, only 302 women answered all the 36 questions of the questionnaire. Five more women were excluded from the analysis due to incomplete response of domain 5 ("life activities"), totalling 297 questionnaires of the 36-item version completely answered. The women were predominantly young (20-34 years), in a relationship, had around 9-11 years of schooling, worked at home and were primipara.

\section{Instrument - WHODAS 2.0 36-item Version}

The 36-item version of the WHODAS 2.0 intends to measure activity function and participation in daily life activities in the 30 days preceding its application. It includes six domains: domain 1 (D1)- cognition (six questions): evaluates communication and thinking activities, including concentration, memory, problem-solving, learning and comprehension; domain 2 (D2)- mobility (five questions): evaluates activities such as standing up, moving around inside the house, going outside the house, and walking a long distance; domain 3 (D3)- self-care (four questions): evaluates hygiene, getting dressed, eating and staying alone; domain 4 (D4)- relationship with people (five questions): evaluates the interactions with others and the difficulties that may be encountered due to adverse health conditions; domain 5 (D5)- life activities (eight questions): evaluates the difficulty with daily life activities (household chores, leisure, work and school); and domain 6 (D6)participation (eight questions): assesses social dimensions, such as joining in community activities, barriers and obstacles in the world surrounding the woman being interviewed, and other problems, such as maintenance of personal dignity. The answer options for each question include: no difficulty, little, moderate, severe or extreme difficulty. The total score ranges from 0 to 100 , and a higher score was indicative of a greater limitation in daily life. ${ }^{11,12}$ All women were invited to answer the 36 questions, but those who had no job or were no longer in school could only answer 32 questions of this version.

\section{Ethics Aspects and Funding}

The local Institutional Review Board approved the study under protocol number 097/2009. All volunteers signed an informed consent form. The study followed the principles of the Declaration of Helsinki, which were reviewed in 2008.

\section{Procedure and Data Management}

The data collected in the interview were entered by a research assistant in the Lime Survey ${ }^{\circledR}$ database, and then transferred to the Statistical Package for the Social Sciences $\left(\right.$ SPSS $^{\circledR}$, IBMSPSS, Inc., Chicago, IL, USA) software. For quality control, researchers performed the data cleaning and logical consistency of the database, in addition to the revision of each question in all domains of the WHODAS 2.0.

\section{Statistical Analysis}

Initially, the mean scores and standard deviations were calculated per domain, for all the women answering the 32 questions, as well as for those answering all the 36 questions of the questionnaire. The internal consistency was verified using Cronbach's $\alpha$. The psychometric properties assessed 
included content validity and construct validity. The factorial structure was examined by exploratory factor analysis (EFA) and confirmatory factor analysis (CFA). ${ }^{18}$ In the EFA, factorial analysis was applied according to the Kaiser-Meyer-Olkin (KMO) measure of sampling adequacy, and the method used for extraction was the Varimax method with Kaiser Normalization. ${ }^{19}$ Pearson's correlation coefficient was used to assess the content and correlations between all of the WHODAS 2.0 domains. Values above the cut-off point of 0.7 were considered as good correlations. $P$ values below 0.05 were considered statistically significant. The software used was SPSS $^{\circledR}$ version 20.0 .

\section{Results}

\section{Reliability of the Whodas 2.0 36-item Brazilian Portuguese Version}

- Table 1 shows that the reliability analysis by Cronbach's $\alpha$ demonstrated values higher than 0.79 . For both groups (the ones who answered 32 and 36 questions), the highest scores were found in D5 ("life activities") and D6 ("participation").

\section{Validity}

The results of the factorial analysis for each domain and question, the factor loading, and the percentage of variance and self-values are shown in - Tables 2 and 3. Questions with factor loading higher than 0.50 were considered significant and were boldfaced. - Table 2 shows the EFA for 32 questions in 6 domains divided into 7 factors, with a total variance of $54.7 \%(\mathrm{KMO}=0.934 ; p<0.001)$. Some questions were not related to their own domains, showing an association with other factors. For example, questions 6.2 ("because of environmental barriers") and 6.3 ("others affect one's dignity") were associated with factor 7, and not with factor 3 , as the remaining questions were grouped in this domain.

The CFA showed a total variance of $53.47 \%$ (KMO $=0.934 ; p<0.001$ ) and reproduced the results of the EFA of 32 questions in 6 domains and 7 factors, identifying the same questions with low factor loading and the remaining concentrated in each domain, that is, interrelated with only one factor (-Table 3). - Fig. 1, which was derived from the CFA, illustrates the variations in the correlations between minimum and maximum values in the 6 domains with 32 questions, detailing each domain, and corresponding loading of each question. There were significant correlations $(p<0.001)$ between each domain and the 7 factors.

- Table 4 shows a moderate to good correlation ( $r=0.571$ for the self-care domain, and $r=0.876$ for the participation domain) in the 6 WHODAS 2.0 domains against the summary score. Domain 6 ("participation") also showed a moderate correlation $(r=0.470$ for D3, and $r=0.694$ for D5a), while the remaining specific domains showed a week correlation for the most part. The highest correlation indexes occurred between D5a ("life activities") and D6 ("participation"), and the lowest occurred among the questions of D3 ("self-care").

Table 1 Reliability of the 32 and the 36 questions of the Brazilian Portuguese version of the WHODAS 2.0 questionnaire, using the mean score and SD for each one of its domains

\begin{tabular}{|l|l|l|l|l|}
\hline Factor (domains) & Mean & SD & N & $\begin{array}{l}\text { Cronbach's Alpha } \\
\text { if item deleted }\end{array}$ \\
\hline With 32 questions of the Brazilian Portuguese version of the WHODAS $2.0^{\text {a }}$ & \multicolumn{2}{l|}{} \\
\hline D1- Cognition & 21.420 & 18.214 & 636 & 0.826 \\
\hline D2- Mobility & 13.760 & 19.013 & 636 & 0.815 \\
\hline D3- Self-care & 5.367 & 12.338 & 636 & 0.844 \\
\hline D4- Getting along & 14.592 & 20.240 & 636 & 0.823 \\
\hline D5a- Life activities: household & 23.354 & 28.348 & 636 & 0.806 \\
\hline D6- Participation & 20.336 & 20.717 & 636 & 0.793 \\
\hline With all 36 questions of the Brazilian Portuguese version of the WHODAS 2.0 & \multicolumn{2}{l|}{} \\
\hline D1- Cognition & 20.108 & 17.392 & 297 & 0.870 \\
\hline D2- Mobility & 10.212 & 15.725 & 297 & 0.863 \\
\hline D3- Self-care & 4.602 & 11.099 & 297 & 0.881 \\
\hline D4- Getting along & 12.675 & 18.231 & 297 & 0.867 \\
\hline D5a- Life activities: household & 20.146 & 27.072 & 297 & 0.850 \\
\hline D5b- Life activities: work and school & 15.897 & 23.646 & 297 & 0.845 \\
\hline D6- Participation & 17.432 & 19.784 & 297 & 0.844 \\
\hline
\end{tabular}

Abbreviations: SD, standard deviation; WHODAS 2.0, World Health Organizaton Disability Assessment Schedule 2.0.

${ }^{a}$ Cronbach's Alpha $=0.929 \rightarrow$ Number of items $=32$ (questions), Cronbach's Alpha $=0.845 \rightarrow$ Number of items $=6$ (domains).

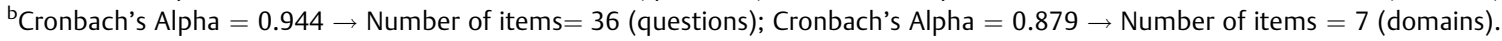


Table 2 Exploratory Factor Analysis of the Brazilian Portuguese version of the WHODAS 2.0 questionnaire in 32 questions and 7 factors (generalized least squares method)

\begin{tabular}{|c|c|c|c|c|c|c|c|}
\hline \multicolumn{8}{|l|}{ Factor* } \\
\hline Questions and their main topics & 1 & 2 & 3 & 4 & 5 & 6 & 7 \\
\hline D11a-Concentration & 0.220 & 0.138 & 0.195 & 0.157 & 0.596 & 0.113 & 0.097 \\
\hline D12a- Remembering to do important things & 0.167 & 0.138 & 0.033 & 0.077 & 0.654 & 0.087 & 0.039 \\
\hline D13a- Problem-solving & 0.140 & 0.101 & 0.149 & 0.199 & 0.614 & 0.020 & 0.167 \\
\hline D14a- Learning a new task & 0.121 & 0.147 & 0.098 & 0.154 & 0.493 & -0.003 & -0.027 \\
\hline D15a- Understanding & 0.030 & 0.119 & 0.124 & 0.286 & 0.476 & 0.059 & 0.069 \\
\hline D16a- Conversation & 0.038 & 0.099 & 0.142 & 0.394 & 0.512 & -0.011 & 0.054 \\
\hline D21a-Standing for long periods & 0.209 & 0.684 & 0.113 & 0.030 & 0.172 & 0.093 & 0.056 \\
\hline D22a- Standing up from sitting & 0.150 & 0.679 & 0.173 & 0.095 & 0.128 & 0.115 & 0.090 \\
\hline D23a- Moving around inside home & 0.126 & 0.632 & 0.139 & 0.108 & 0.159 & 0.174 & 0.066 \\
\hline D24a- Getting out of home & 0.157 & 0.673 & 0.195 & 0.253 & 0.132 & 0.216 & 0.005 \\
\hline D25a- Walking a long distance & 0.332 & 0.595 & 0.209 & 0.125 & 0.120 & 0.171 & 0.096 \\
\hline D31a- Washing your whole body & 0.155 & 0.177 & 0.113 & 0.059 & 0.076 & 0.817 & 0.076 \\
\hline D32a- Getting dressed & 0.130 & 0.250 & 0.098 & 0.085 & -0.017 & 0.806 & 0.111 \\
\hline D33a- Eating & 0.117 & 0.066 & 0.173 & 0.062 & 0.095 & 0.494 & 0.093 \\
\hline D34a- Staying by self for a few days & 0.114 & 0.143 & 0.091 & 0.120 & 0.158 & 0.214 & 0.202 \\
\hline D41a- Dealing with strangers & 0.122 & 0.050 & 0.118 & 0.573 & 0.251 & 0.101 & 0.091 \\
\hline D42a- Maintaining a friendship & 0.151 & 0.114 & 0.068 & 0.782 & 0.137 & 0.080 & 0.127 \\
\hline D43a- Getting along with people close & 0.076 & 0.145 & 0.110 & 0.555 & 0.216 & 0.077 & 0.208 \\
\hline D44a- Making new friends & 0.131 & 0.115 & 0.129 & 0.748 & 0.200 & 0.025 & 0.127 \\
\hline D45a- Sexual activities & 0.278 & 0.177 & 0.234 & 0.270 & 0.219 & 0.093 & 0.153 \\
\hline D51a- Household responsibilities & 0.765 & 0.225 & 0.245 & 0.167 & 0.155 & 0.138 & 0.079 \\
\hline D52a- Do important household tasks well & 0.742 & 0.184 & 0.252 & 0.163 & 0.173 & 0.137 & 0.108 \\
\hline D53a- Do all needed household work & 0.754 & 0.271 & 0.276 & 0.115 & 0.197 & 0.211 & 0.121 \\
\hline D54a- Household work performed as quickly as needed & 0.605 & 0.293 & 0.327 & 0.139 & 0.245 & 0.142 & 0.134 \\
\hline D61a- Joining in community activities & 0.334 & 0.264 & 0.330 & 0.345 & 0.145 & 0.127 & 0.187 \\
\hline D62a- Because of environmental barriers & 0.113 & 0.060 & 0.180 & 0.184 & 0.083 & 0.175 & 0.699 \\
\hline D63a- Others affect one's dignity & 0.139 & 0.093 & 0.116 & 0.268 & 0.091 & 0.078 & 0.579 \\
\hline D64a- Health affects time consumption & 0.235 & 0.209 & 0.645 & 0.095 & 0.133 & 0.166 & 0.128 \\
\hline D65a- Health affects one's emotions & 0.311 & 0.201 & 0.597 & 0.146 & 0.233 & 0.123 & 0.198 \\
\hline D66a- Health affects family finances & 0.225 & 0.120 & 0.705 & 0.093 & 0.102 & 0.165 & 0.056 \\
\hline D67a- Health affects family & 0.199 & 0.210 & 0.657 & 0.144 & 0.131 & 0.055 & 0.080 \\
\hline D68a- Doing things for relaxation or pleasure & 0.269 & 0.208 & 0.462 & 0.200 & 0.242 & 0.116 & 0.328 \\
\hline \% Variance & 320.71 & 60.35 & 40.15 & 30.77 & 20.79 & 30.04 & 10.87 \\
\hline \% Cumulative variance & 320.71 & 390.07 & 430.22 & 460.99 & 490.78 & 520.81 & 540.69 \\
\hline
\end{tabular}

Abbreviation: WHODAS 2.0, World Health Organizaton Disability Assessment Schedule 2.0.

Notes: Total $\mathrm{R}^{2}=54.7 \% \mathrm{KMO}=0.934 ; p<0.001$.

* Rotated factor matrix (Varimax method with Kaiser Normalization).

\section{Discussion}

The Adequacy of the Brazilian Portuguese Language version of the WHODAS 2.0

We validated the Brazilian Portuguese version of WHODAS 2.0 that had already been translated and cross-culturally adapted from the original English version in another study. ${ }^{13}$
When applied to a population of women during the reproductive age, it showed appropriate psychometric properties and better results than the European Portuguese version. ${ }^{14}$

\section{Internal Consistency and Reliability}

We found a slight difference between Cronbach's $\alpha$ values when analyzing both groups. Even excluding one question 
Table 3 Confirmatory Factor Analysis of the Brazilian Portuguese version of the WHODAS 2.0 questionnaire in 32 questons, 6 domains and 7 factors (maximum likelihood method)

\begin{tabular}{|c|c|c|c|c|c|c|c|}
\hline \multirow[t]{2}{*}{ Questions and their main topics } & \multicolumn{7}{|l|}{ Factor } \\
\hline & 1 & 2 & 3 & 4 & 5 & 6 & 7 \\
\hline D11a- Concentration & 0.141 & 0.194 & 0.202 & 0.153 & 0.593 & 0.122 & 0.099 \\
\hline D12a- Remembering to do important things & 0.138 & 0.032 & 0.154 & 0.071 & 0.645 & 0.090 & 0.047 \\
\hline D13a- Problem-solving & 0.100 & 0.147 & 0.125 & 0.195 & 0.611 & 0.027 & 0.167 \\
\hline D14a- Learning a new task & 0.145 & 0.099 & 0.110 & 0.150 & 0.491 & 0.003 & -0.028 \\
\hline D15a- Understanding & 0.120 & 0.122 & 0.019 & 0.282 & 0.462 & 0.060 & 0.072 \\
\hline D16a- Conversation & 0.099 & 0.139 & 0.030 & 0.387 & 0.502 & -0.009 & 0.052 \\
\hline D21a-Standing for long periods & 0.677 & 0.116 & 0.188 & 0.034 & 0.180 & 0.095 & 0.052 \\
\hline D22a-Standing up from sitting & 0.676 & 0.176 & 0.127 & 0.097 & 0.136 & 0.114 & 0.087 \\
\hline D23a- Moving around inside home & 0.612 & 0.145 & 0.110 & 0.111 & 0.165 & 0.171 & 0.068 \\
\hline D24a- Getting out of home & 0.654 & 0.194 & 0.139 & 0.248 & 0.148 & 0.210 & 0.018 \\
\hline D25a- Walking a long distance & 0.600 & 0.212 & 0.308 & 0.127 & 0.132 & 0.174 & 0.098 \\
\hline D31a- Washing your whole body & 0.189 & 0.106 & 0.135 & 0.061 & 0.074 & 0.837 & 0.070 \\
\hline D32a- Getting dressed & 0.267 & 0.097 & 0.118 & 0.088 & -0.016 & 0.769 & 0.110 \\
\hline D33a- Eating & 0.076 & 0.172 & 0.105 & 0.064 & 0.090 & 0.487 & 0.095 \\
\hline D34a- Staying by self for a few days & 0.149 & 0.091 & 0.103 & 0.123 & 0.157 & 0.212 & 0.200 \\
\hline D41a- Dealing with strangers & 0.057 & 0.111 & 0.111 & 0.560 & 0.259 & 0.107 & 0.097 \\
\hline D42a- Maintaining a friendship & 0.116 & 0.070 & 0.139 & 0.768 & 0.156 & 0.085 & 0.120 \\
\hline D43a- Getting along with people close & 0.141 & 0.111 & 0.063 & 0.555 & 0.227 & 0.080 & 0.200 \\
\hline D44a- Making new friends & 0.119 & 0.127 & 0.119 & 0.725 & 0.220 & 0.025 & 0.132 \\
\hline D45a- Sexual activities & 0.181 & 0.240 & 0.262 & 0.269 & 0.228 & 0.093 & 0.155 \\
\hline D51a- Household responsibilities & 0.242 & 0.266 & 0.738 & 0.169 & 0.172 & 0.147 & 0.088 \\
\hline D52a- Do important household tasks well & 0.201 & 0.271 & 0.718 & 0.165 & 0.188 & 0.146 & 0.115 \\
\hline D53a- Do all needed household work & 0.290 & 0.296 & 0.727 & 0.120 & 0.209 & 0.220 & 0.123 \\
\hline D54a- Household work performed as quickly as needed & 0.308 & 0.342 & 0.579 & 0.142 & 0.258 & 0.149 & 0.130 \\
\hline D61a- Joining in community activities & 0.270 & 0.338 & 0.312 & 0.347 & 0.159 & 0.131 & 0.182 \\
\hline D62a- Because of environmental barriers & 0.060 & 0.184 & 0.098 & 0.189 & 0.085 & 0.183 & 0.700 \\
\hline D63a- Others affects one's dignity & 0.095 & 0.127 & 0.129 & 0.277 & 0.100 & 0.084 & 0.527 \\
\hline D64a- Health affects time consumption & 0.219 & 0.616 & 0.218 & 0.098 & 0.149 & 0.169 & 0.132 \\
\hline D65a- Health affects one's emotions & 0.213 & 0.582 & 0.286 & 0.152 & 0.245 & 0.137 & 0.192 \\
\hline D66a- Health affects family finances & 0.130 & 0.693 & 0.201 & 0.093 & 0.115 & 0.175 & 0.063 \\
\hline D67a- Health affects family & 0.212 & 0.664 & 0.171 & 0.146 & 0.142 & 0.063 & 0.077 \\
\hline D68a- Doing things for relaxation or pleasure & 0.210 & 0.464 & 0.246 & 0.207 & 0.248 & 0.128 & 0.313 \\
\hline \% Variance & 320.51 & 50.99 & 40.19 & 30.58 & 20.66 & 20.83 & 10.69 \\
\hline \% Cumulative variance & 320.51 & 380.50 & 420.69 & 460.27 & 480.93 & 510.77 & 530.46 \\
\hline
\end{tabular}

Abbreviation: WHODAS 2.0, World Health Organizaton Disability Assessment Schedule 2.0.

Notes: Total $\mathrm{R}^{2}=53.47 \% \mathrm{KMO}=0.934 ; p<0.001$.

(D5b - "work and school activities"), the Cronbach's $\alpha$ value maintained good internal consistency. Similar findings were reported in other studies, such as in a survey conducted in Canada among adults suffering from inflammatory arthritis. $^{20}$

Compared with other studies of cross-cultural adaptation and construct validity, our results were similar to the Chinese version applied to elderly adults or institutionalized patients. ${ }^{21}$ In the Spanish version, internal validation showed a higher Cronbach's $\alpha$ value for patients with schizophrenia. ${ }^{22}$ In contrast, it ranged from 0.68 to 0.91 for elderly individuals with hearing loss in the United States, ${ }^{23}$ while a recent study investigating patients with chronic morbid conditions showed values from 0.70 to $0.97 .^{24}$ Therefore, the internal 


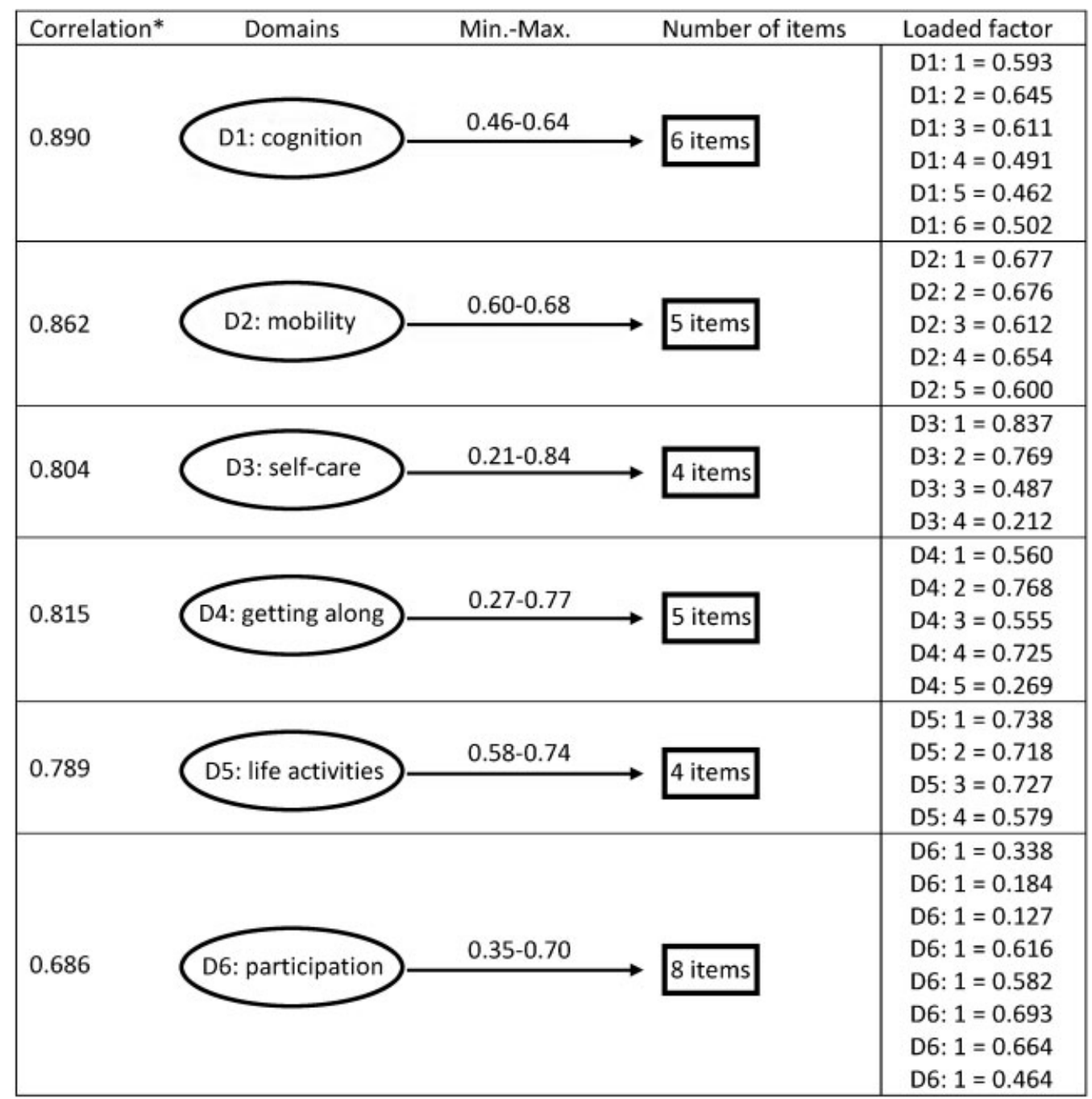

Fig. 1 Confirmatory Factor Analysis (CFA) of the Brazilian Portuguese version of the WHODAS 2.0 questionnaire with 36 questions and 6 domains (maximum likelihood method) for disability $\left({ }^{*} p<0.01\right)$.

validation of the WHODAS 2.0 has been performed in different cultures and populations. We did not know the reasons why the versions perform differently according to different cultures and populations; however, we can hypothesize that the understanding of how illness and disability are perceived by the respondants is involved in this result. In addition, we cannot make an exact parallel with previous available information, considering that, to the best of our knowledge, this is the first time this instrument is applied in a female population regarding the reproductive process.

Table 4 Correlation of the WHODAS 2.0 with all domains and the summary score $(n=636)$

\begin{tabular}{|l|l|l|l|l|l|l|l|}
\hline WHODAS 2.0 & D1 & D2 & D3 & D4 & D5a & D6 & Summary Score \\
\hline D1- Cognition & 1 & 0.430 & 0.286 & 0.544 & 0.494 & 0.503 & 0.743 \\
\hline D2- Mobility & & 1 & 0.463 & 0.424 & 0.613 & 0.561 & 0.757 \\
\hline D3- Self-care & & & 1 & 0.320 & 0.455 & 0.470 & 0.571 \\
\hline D4- Getting along & & & & 1 & 0.487 & 0.560 & 0.724 \\
\hline D5a- Life activities & & & & & 1 & 0.694 & 0.825 \\
\hline D6- Participation & & & & & & 1 & 0.876 \\
\hline Summary Score & & & & & & & 1 \\
\hline
\end{tabular}

Abbreviation: WHODAS 2.0, World Health Organizaton Disability Assessment Schedule 2.0.

Note: All $p<0.001$. 


\section{The WHODAS 2.0 Domains and Mean Scores}

The highest mean scores for this version when considering all cases within the 32-question group were concentrated in the following domains: D1 ("concentration, memory, problemsolving, learning and comprehension"); D5 ("life activities: household"); and D6 ("participation"). This suggests that in this population there was a greater dysfunction for these domains, irrespective of the fact that the respondants had or not experienced severe maternal morbidity. They differed from those of a study involving patients with spinal cord injury, in which the highest means were concentrated in D2 ("mobility"), D3 ("self-care") and D5 ("life activities"), findings that would be obviously expected. ${ }^{25}$ In a multicenter European study with 1,119 patients suffering from different chronic diseases, the highest scores were concentrated in D2 ("mobility"), D5 ("life activities") and D6 ("participation"). ${ }^{26}$ These results suggest that the burden of morbidity interferes with the functional capacity of the individuals, and the instrument is capable of identifying the domains in which disability is greater, confirming its importance for planning health care for these populations. Specifically for this population (women who have experienced an episode of severe maternal morbidity and women who have not), significant differences associated with the occurrence of severe maternal morbidity were found for D2 ("mobility"), D5a ("household acitivities"), D6 ("participation") and the general score. ${ }^{27}$ These results do not seem surprising if we think in the possible limitations and dysfunctioning that women who had a severe morbidity could have due to the care of a baby in the context of local society.

\section{Construct Validity}

The interdomain correlation analysis offered additional information: the weakest correlations were identified for D1 and D3 ("cognition" and "self-care"), D3 and D4 ("self-care" and "relationship with people"), and the strongest correlations were identified for D2 and D5a ("mobility" and "household activities") and D5a and D6 ("household activities" and "participation"). Such findings reinforce the relationships among these activities.

The structural relationship between domains is demonstrated by the EFA and the CFA. On the CFA and EFA, this may be confirmed by intercorrelations among some questions in different factors. Three questions in 3 different domains (D34a, D45a and D61a) did not show significant loading factor in any of the 7 factors. Question 34a is about "difficulty in staying alone for a few days" in the 30 days preceding the application of the questionnaire. We believe that this question does not apply to our study population, since these women had children, domestic and family demands, and were rarely alone. Question D45a is about "sexual activity" over the previous 30 days. We could not justify the lack of a significant factor loading. Question D61a is about "how difficult it is to participate in community activities with other people". Similar to question 34a, it did not seem to apply to our study's population.

Two other questions (D62a and D63a) were not grouped in the same factor on the EFA, unlike the remaining questions on D6. Both questions derive from Chapter 9 ("Community, social and civic life"), and belong to the topic "Community life (how people are affected by attitudinal components of society and human rights)". ${ }^{5}$ Here, it appears that these questions are really not directly related to the domain. ${ }^{6}$

The questions that individually reflected a higher significance for the evaluation of difficulties in each domain, that is, those that had a higher factor loading on the CFA were: D1.2-"remembering to do important things"; D2.1-"remaining standing for prolonged periods of time, such as 30 minutes"; D3.1-"washing the whole body"; D4.2-"maintaining a friendship"; D5.1-“taking care of domestic responsibilities"; and D6.6-"how much her health influences her pocket or the financial resources of her family". Of these 6 questions, 4 are present in the short WHODAS 2.0 version, which contains 12 questions. This leads us to reflect on the power of analysis of this short version, which in the clinical practice is easier and faster to apply. Several women who were interviewed required referrals to other health profissionals and healthcare facilities at the end of the interview. The short version was applied in a study involving 124 patients suffering from psychic morbid conditions, and the same properties as the 36 -item version were identified. ${ }^{28}$ A future analysis using the short version for our data may confirm these results.

A recent systematic review on the use of the WHODAS 2.0 identified that it has already been translated into 47 languages and dialects, and used in 27 areas of research, with psychiatry being the most common. ${ }^{29}$ The review also showed thtat the instrument seems to be useful in a variety of settings and populations, which reinforces the results of the current study.

\section{Limitations}

Our results cannot be generalized, and this is the main limitation of the study. On the other hand, the study population was composed of women in reproductive age, who are deemed to be more vulnerable and were less extensively investigated by other studies. Furthermore, the socioeconomic and cultural aspects of these women, who live in an upper-middle-income country, contribute to a greater chance of developing certain maternal complications along with several barriers to access health care facilities.

\section{Conclusion}

Our results may contribute to raise awareness about the issue of disabilities among women experiencing morbidity during childbirth, and that has the potential of fomenting the creation of public policies for this population group. The results of our study support the use of the WHODAS 2.0 for studies or for the routine data assessment of the impact of maternal morbidities on the lives and functioning of women.

\section{Supplementary Data}

The full Brazilian Portuguese version of the WHODAS 2.0 can be accessed at the following link (- supplementary material)

\section{Acknowledgments}

We acknowledge the other members of the COMMAG study group who participated in all steps of the current 
study: Juliana P. Santos, Dulce M. Zanardi, Maria L. Costa, Rodrigo P. Camargo, Gustavo N. Cecchino, Jamile C. Bussadori, and Renato T. Souza.

This study was sponsored by the Brazilian National Research Council (CNPq research grant 471142/2011-5).

The authors have no conflicts of interest to declare.

\section{References}

1 World Health Organization [Internet]Women's health. Geneva: WHO; 2016 [cited 2016 Sep 18]. Available from: http://www.who. int/topics/womens_health

2 World Health Organization [Internet]Women and health: today's evidence tomorrow's agenda. Geneva: WHO; 2009 [cited 2016 Sep 18]. Available from: http://apps.who.int/iris/bitstream/10665/ 44168/1/9789241563857_eng.pdf

3 Ferdous J, Ahmed A, Dasgupta SK, et al. Occurrence and determinants of postpartum maternal morbidities and disabilities among women in Matlab, Bangladesh. J Health Popul Nutr 2012;30(02): 143-158

4 Koblinsky M, Chowdhury ME, Moran A, Ronsmans C. Maternal morbidity and disability and their consequences: neglected agenda in maternal health. J Health Popul Nutr 2012;30(02): 124-130

5 World Health Organization [Internet]International Classification of Functioning, Disability and Health: ICF. Geneva: WHO; 2001 [cited 2016 Sep 18]. Available from: http://www.who.int/classifications/icf/en/

6 Brandt DE, Ho PS, Chan L, Rasch EK. Conceptualizing disability in US national surveys: application of the World Health Organization's (WHO) International Classification of Functioning, Disability, and Health (ICF) framework. Qual Life Res 2014;23(10): 2663-2671

7 World Health Organization [Internet]Summary: world report on disability. Geneva: WHO; 2011 [cited 2016 Sep 18]. Available from: http://www.who.int/disabilities/world_report/2011/accessible_en.pdf

8 Peeters G, Dobson AJ, Deeg DJ, Brown WJ. A life-course perspective on physical functioning in women. Bull World Health Organ 2013; 91(09):661-670

9 World Health OrganizationWorld Health Survey 2002-2004. Geneva: WHO; 2004

10 Instituto Brasileiro de Geografia e Estatística[Demographic census: general characteristcs of population, religion and individuals with deficiency]. Rio de Janeiro: IBGE; 2010. Portuguese.

11 Üstün TB, Kostanjsek N, Chatterji S, Rehm J, Eds. Measuring health and disability: manual for WHO Disability Assessment Schedule (WHODAS 2.0) [Internet]. Geneve: WHO; 2010 [cited 2016 Sep 18]. Available from: http://apps.who.int/iris/bitstream/10665/ 43974/1/9789241547598_eng.pdf

12 Ustün TB, Chatterji S, Kostanjsek N, et al; WHO/NIH Joint Project. Developing the World Health Organization Disability Assessment Schedule 2.0. Bull World Health Organ 2010;88(11):815-823

13 Silveira C, Parpinelli MA, Pacagnella RC, et al. [Cross-cultural adaptation of the World Health Organization Disability Assessment Schedule (WHODAS 2.0) into Portuguese]. Rev Assoc Med Bras (1992) 2013;59(03):234-240
14 Silva C, Coleta I, Silva AG, et al. Adaptation and validation of WHODAS 2.0 in patients with musculoskeletal pain. Rev Saude Publica 2013;47(04):752-758

15 Pasquali L. [Psychometry: theory of tests in psychology and education]. Petrópolis: Vozes; 2009. [Validity of tests]; p. 58191. Portuguese.

16 Cecatti JG, Souza JP, Parpinelli MA, et al; Brazilian Network for Surveillance of Severe Maternal Morbidity. Brazilian network for the surveillance of maternal potentially life threatening morbidity and maternal near-miss and a multidimensional evaluation of their long term consequences. Reprod Health 2009;6:15

17 Pacagnella RC, Cecatti JG, Camargo RP, et al. Rationale for a longterm evaluation of the consequences of potentially life-threatening maternal conditions and maternal "near-miss" incidents using a multidimensional approach. J Obstet Gynaecol Can 2010;32(08): 730-738

18 Hair JF Jr, Anderson RE, Taham RL, Black WC. [Multivariate analysis of data]. 5th ed. Porto Alegre: Bookman; 2005. [Factorial analysis]; p. 89-127. Portuguese.

19 Floyd FJ, Widaman KF. Factor analysis in the development and refinement of clinical assessment instruments. Psychol Assess 1995;7(03):286-299

20 Baron M, Schieir O, Hudson M, et al. The clinimetric properties of the World Health Organization Disability Assessment Schedule II in early inflammatory arthritis. Arthritis Rheum 2008;59(03): 382-390

21 Chiu TY, Yen CF, Chou CH, et al. Development of traditional Chinese version of World Health Organization disability assessment schedule 2.0 36-item (WHODAS 2.0) in Taiwan: validity and reliability analyses. Res Dev Disabil 2014;35(11):2812-2820

22 Guilera G, Gómez-Benito J, Pino O, et al. Utility of the World Health Organization Disability Assessment Schedule II in schizophrenia. Schizophr Res 2012;138(2-3):240-247

23 Chisolm TH, Abrams HB, McArdle R, Wilson RH, Doyle PJ. The WHO-DAS II: psychometric properties in the measurement of functional health status in adults with acquired hearing loss. Trends Amplif 2005;9(03):111-126

24 Pösl M, Cieza A, Stucki G. Psychometric properties of the WHODASII in rehabilitation patients. Qual Life Res 2007;16(09): 1521-1531

25 Wolf AC, Tate RL, Lannin NA, Middleton J, Lane-Brown A, Cameron ID. The World Health Organization Disability Assessment Scale, WHODAS II: reliability and validity in the measurement of activity and participation in a spinal cord injury population. J Rehabil Med 2012;44(09):747-755

26 Garin O, Ayuso-Mateos JL, Almansa J, et al; MHADIE consortium. Validation of the "World Health Organization Disability Assessment Schedule, WHODAS-2" in patients with chronic diseases. Health Qual Life Outcomes 2010;8:51

27 Silveira C, Parpinelli MA, Pacagnella RC, et al. A cohort study of functioning and disability among women after severe maternal morbidity. Int J Gynaecol Obstet 2016;134(01):87-92

28 Norton J, de Roquefeuil G, Benjamins A, Boulenger JP, Mann A. Psychiatric morbidity, disability and service use amongst primary care attenders in France. Eur Psychiatry 2004;19(03):164-167

29 Federici S, Bracalenti M, Meloni F, Luciano JV. World Health Organization disability assessment schedule 2.0: An international systematic review. Disabil Rehabil 2016:1-34; [Epub ahead of print] 